\title{
PF Merger WOUld Do, TOO: A RePly to Zhang (1997)*
}

\author{
David Ta-Chun SHEN \\ Department of English, National Taiwan Normal University \\ david.shen@std.ntnu.edu.tw
}

\begin{abstract}
The analysis for the phenomenon that prepositions may or may not undergo the third tone sandhi in Mandarin in Zhang (1997) is reviewed. She considers that this phenomenon is short of sound coverage and couches her analysis in the framework of Optimality Theory (OT). However, upon scrutiny, Zhang's analysis invites unnecessary questions. The postulation of two "constituent strength" constraints is with no foundation. It is difficult to grab the idea behind the constituentstrength concept even till now. Related to the concept, the non-specification of a prepositional phrase is not clear. Instead, the syntactic feature manifestation could mark a preposition's uniqueness. In addition, the misuse of the Generalized Alignment and stipulations toward the evaluations in OT are spotted, too. My synthetic approach, based on the extant and developing knowledge about constituency, PF merger, and Shih's (1997) foot formation, shows that for this phenomenon, no new device is needed.
\end{abstract}

\section{Keywords}

Mandarin, third tone sandhi, PF merger

\section{Izvleček}

Članek se osredotoča na analizo, ki jo predlaga Zhang (1997), in ponovno prouči trditev, da v primeru predlogov v sodobni kitajščini ne pride nujno do glasovne spremembe tretjega tona. Zhang (1997) namreč meni, da ta pojav ni zadostno podkrepljen z zvočnimi primeri in razvije svoj pristop v okviru optimalnostne teorije (OT). Kljub veliki natančnosti taka analiza sproža vsrto nepotrebnih vprašanj, kot je na primer smisel predpostavke o dveh omejitvah "moči konstituentov", predvsem pa je še danes težko razumeti ideje, ki stojijo za tem konceptom. V tem kontekstu je nezadovoljivo pojasnjena tudi tonska nedoločenost predložne zveze. Avtor v zameno ponudi pristop, ki temelji na manifestaciji sintaktičnih lastnosti in bi utegnil obvladati edinstvenost predložnih zvez. Poleg tega je bila ugotovljena napačna uporaba teorije splošnih formacij (GA) in pogojev za ocenjevanje v OT. S sintetičnim pristopom, ki temelji na razpoložljivem znanju o sintaktični strukturi, na strnitvi fonoloških struktur (PF zdruzitev) in na oblikovanju stopic po Shih (1997), avtor pokaže, da za razlago tega pojava ne potrebujemo novih sredstev.

\section{Ključne besede}

Mandarinščina, glasovna sprememba tretjega tona, PF združitev

\footnotetext{
* I would like to thank the two anonymous reviewers of Acta Linguistica Asiatica's encouragement. Moreover, their comments help me fine-tune the article and its presentation and inspire me to think the argumentation more carefully. All remaining errors, however, are mine to blame.
}

Acta Linguistica Asiatica, 1(2), 2011.

ISSN: 2232-3317, http://revije.ff.uni-lj.si/ala/

DOI: 10.4312/ala.1.2.9-24 


\section{Introduction}

The third tone sandhi (TS3) is the ever-lasting issue in the Mandarin phonology. The phenomenon per se is quite straightforward: the first third tone (T3) becomes a second tone (T2) when followed by another T3. However, the crux lies in when there are more than two consecutive T3s together. How does phonology interact with morphology, syntax, and semantics to derive the surface representations (SRs)? What roles do the above modules play? It is this interface characteristic that squeezes out abundance of the literature.

Under this context, Zhang (1997) has directed the focus to a sub-phenomenon of TS3 where she considered that all the previous literature has fallen short of a satisfactory analysis (Zhang, 1997, p. 297-304). This sub-phenomenon is termed the avoidance of TS3. And it is further divided into two types. In (1) below, the sentences all contain the structure [ [xp $\left.\sigma^{\mathrm{a}} \sigma^{\mathrm{b}}\right] \sigma^{\mathrm{c}}$ ]. Only when $\sigma^{\mathrm{a}}$ is a preposition, could that syllable have its SR as T3 or (sandhied) T2. This type is called "“category dependency in avoidance of TS [tone sandhi]"” (Zhang, 1997, p. 295).

(1) Category dependency in avoidance of TS (Zhang, 1997, p. 293-295)

a. $\sigma^{\mathrm{a}}$ prepositional

$\begin{array}{lllll}\alpha . & \text { 狗 } & \text { 比 } & \text { 馬 } & \text { 小。 } \\ & \text { Gou } & {[\text { [bi }} & \text { ma] } & \text { xiao]. } \\ & \text { dog } & \text { than } & \text { horse } & \text { small } \\ \text { UR } & 3 & 3 & 3 & 3^{1} \\ \text { SR } & 2 & 3 & 2 & 3 \\ \text { SR } & 3 & 2 & 2 & 3\end{array}$

"A dog is smaller than a horse."

B. 馬 往 北走。

Ma [[wang bei] zou]. horse to north walk

$\begin{array}{lllll}\text { UR } & 3 & 3 & 3 & 3\end{array}$

$\begin{array}{lllll}\mathrm{SR} & 2 & 3 & 2 & 3\end{array}$

$\begin{array}{lllll}\mathrm{SR} & 3 & 2 & 2 & 3\end{array}$

"The horse walked to the north."

\footnotetext{
${ }^{1}$ UR means underlying representation, i.e. underlying tone in the present study. The same applies to SR.
} And the numeral two and three stand for $\mathrm{T} 2$ and $\mathrm{T} 3$, respectively. 
b. $\sigma^{\mathrm{a}}$ non-prepositional

$\begin{array}{lllll}\alpha . & \text { 馬 } & \text { 很 } & \text { 少 } & \text { 吼。 } \\ & \text { Ma } & \text { [[ hen } & \text { shao] } & \text { hou]. } \\ \text { UR } & \text { horse } & \text { very } & \text { seldom } & \text { roar } \\ \text { SR } & 3 & 3 & 3 & 3 \\ & 2 & 2 & 3\end{array}$

"Horses seldom roar."

$\begin{array}{lllll}\beta . & \text { 有 } & \text { 兩 碗 } & \text { 米。 } \\ & \text { You } & \text { [[liang } & \text { wan] } & \text { mi]]. } \\ & \text { have } & \text { two } & \text { bowl } & \text { rice } \\ \text { UR } & 3 & 3 & 3 & 3 \\ \text { SR } & 3 & 2 & 2 & 3\end{array}$

"There are two bowls of rice."

The other type is called "structure dependency in avoidance of TS" (Zhang, 1997, p. 295). For this type, prepositions and other categories behave together. It is structure differences that make the avoidance of TS possible or not.

(2) Structure dependency in avoidance of TS (Zhang, 1997, p. 296)

a. $\left[\left[\sigma^{\mathrm{c}}\left[\mathrm{xP} \sigma^{\mathrm{a}} \sigma^{\mathrm{b}}\right]\right] \sigma^{\mathrm{d}}\right]$

a. 買 小 馬好。

[Mai [xiao ma]] hao.

buy small horse good

$\begin{array}{lllll}\text { UR } & 3 & 3 & 3 & 3\end{array}$

$\begin{array}{lllll}\text { SR } & 3 & 2 & 2 & 3\end{array}$

"It is good to buy small horses."

B. 比小狗 懶

[bi [xiao gou ] lan

than small dog lazy

$\begin{array}{lllll}\text { UR } & 3 & 3 & 3 & 3\end{array}$

$\begin{array}{lllll}\text { SR } & 3 & 2 & 2 & 3\end{array}$

"to be lazier than the small dog"

b. $\left[\sigma^{\mathrm{e}}\left[\left[\mathrm{XP} \sigma^{\mathrm{a}} \sigma^{\mathrm{b}}\right]\left[\mathrm{XP} \sigma^{\mathrm{c}} \sigma^{\mathrm{d}}\right]\right]\right]$

a. 鬼打傘買酒。

Gui [[da san] [mai jiu]].

ghost take umbrella buy wine

$\begin{array}{llllll}\text { UR } & 3 & 3 & 3 & 3 & 3\end{array}$

$\begin{array}{llllll}\text { SR } & 3 & 2 & 3 & 2 & 3\end{array}$

"The ghost bought wine with an umbrella." 


$\begin{array}{llllll}\beta . & \text { 馬 } & \text { 給 } & \text { 狗 } & \text { 洗 } & \text { 澡。 } \\ & \text { Ma } & \text { [[gei } & \text { gou] } & \text { [xi } & \text { zao]]. } \\ & \text { horse } & \text { for } & \text { dog } & \text { wash } & \text { bath } \\ \text { UR } & 3 & 3 & 3 & 3 & 3 \\ \text { SR } & 3 & 2 & 3 & 2 & 3\end{array}$

"The horse bathed the dog."

In (2a), $\sigma^{c}$ preserves the T3 regardless of its part of speech. Reversely, in (2b), $\sigma^{a}$ has to change to $\mathrm{T} 2$, but again, regardless of its part of speech.

Based on her analysis, Zhang (1997) concludes that the Optimality Theory (OT) is superior to a rule-based analysis. However, a closer look at the analysis would show that this conclusion has been formed on a shaky foundation. Moreover, with the progress of the Minimalist Program and the initiation of the Distributed Morphology, one is equipped with the post-syntactic movement/P(honological)F(orm) merger/morphological merger, among other things. This mechanism provides the way to explain how a syntactic non-constituent could form a TS domain, like the reading 2323 of (1a).

Therefore, the avoidance of TS need not be the result of constraint ranking. Actually, as will be demonstrated below, it is the result of syntax-all-the-way-down, PF merger, and Shih's (1997) prosodic formation algorithm.

The organization of this study is as follows. In section 2, two concerns toward Zhang's analysis will be raised. The avoidance fact will then be re-examined in section 3. Section 4 concludes this paper.

\section{Two Concerns}

In this section, two parts which motivate me to reanalyze the phenomenon are going to be discussed.

In order to decide which underlying T3 will surface up as T3, Cinque's (1993) null stress theory has been reinterpreted as the manifestation of "constituent strength" (Zhang, 1997, p. 304-305). Originally, Cinque's idea is to predict phrasal/sentential and compound main stress through the syntactic structure, which would then make language-particular stress assignment redundant. The gist of his theory is that the most embedded constituent will have the primary stress (Cinque, 1993, p. 245). Therefore, if a complement is present, it will receive the primary stress. If not, the head will receive the stress, instead. A specifier and/or pre-modifier will always be weak in stress. Borrowing this idea, Zhang (1997) has posited two relevant constraints as in (3). 
(3) Constituent strength related constraints (Zhang, 1997, p. 306)

a. Parse Underlying Tone of an Absolutely Strong Node (PTAS)

The underlying tone of a strong constituent which is not dominated by any w node must be parsed.

b. Parse Underlying Tone of a Relatively Strong Node (PTRS)

The underlying tone of a strong constituent which is dominated by at least one w node must be parsed.

In (3), $w$ means that a constituent has weak strength. If a constituent has a strong strength, it bears a mark of $s$. And to be parsed means that a tone has to be unchanged. As an example, (4) would have the following constituent strength distribution.

(4) Constituent strength distribution of Ma hen shao hou. "Horses rarely roar." (Zhang, 1997, p. 305)

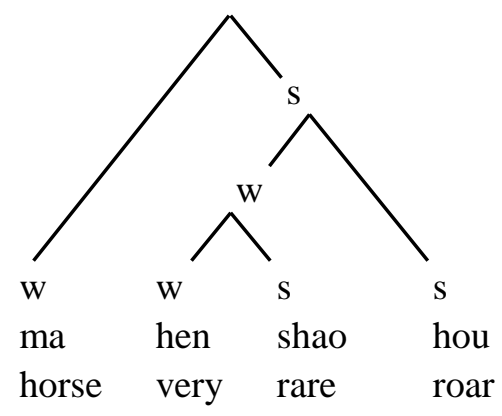

For hen shao, shao is strong because it is the head. Hen is therefore weak. Because hen shao and $m a$ are pre-modifier and specifier respectively, they are both weak, while hou is the most embedded with two s's assigned. Because hou is not dominated by any $\mathrm{w}$, hou will not violate PTAS only if it has T3 in the surface. Although PTAS is irrelevant to shao, PTRS is: shao is dominated by w once-PTRS will not be violated if it has $\mathrm{T} 3$ in the surface.

There is, however, a serious gap. What is the nature of the concept of constituent strength? The most probable possibility, stress, was denied as she had realized the complex interaction between stress and tone and tried to eschew this problem:

...I will regard Cinque's contrast of s/w stress as contrast of s/w constituent strength rather than as a reflection of stress directly. (Zhang, 1997, p. 304)

The situation now goes back to the very beginning: what is the constituent strength? The innovative use of somebody else's idea or the creative use of one's very own idea is more than welcome for any scientific study, but this kind of use should not be taken for granted and should be reasoned. In the present case, a more elaborated 
explanation is a must in order to make the use of constituent strength valid. Or, its use at that time was too novel to be defined, so it is the subsequent works (e.g. Wee, 2008) that are the places to look for. It seems not to be the case, either. This situation makes the status of constituent strength questionable. And one cannot help but think that the so-called constituent strength is merely a stipulation which tries to endorse itself through Cinque (1993) and at the same time hopes no controversy incurred through some vague rhetoric.

The other function of the constituent strength is to deal with the prepositionpertinent TS avoidance phenomenon. A prepositional phrase is not specified for $\mathrm{s}$ and w. Instead, a preposition and its complement are left blank. A prepositional phrase could be an sw or ws combination. It can be said that Zhang has utilized the nonspecification for prepositional phrases. There are two questions about this device. Other than visualizing the special status of a preposition, what motives this move of non-specification? I consider that the special status of a preposition already can be manifested by the means of its feature make-up, i.e. [-N, -V]. The non-specification approach is nothing but another way to re-package the old information. The postulation of a new device should be motivated, otherwise it should be avoided. The nonspecification is no superior to the feature manifestation, if not inferior. The other question is: why are there only two aforementioned combinations? What excludes the combinations of ss and ww when these two alternatives could also produce the desired results? This question has never been discussed in the text or in an endnote. The nonspecification gives out the freedom and at the same time the unwanted logical possibilities. To resolve this with another constraint or qualification only makes things more complicated, compared with the commonly-assumed feature make-up practice. In sum, until Zhang is willing to provide more evidence on the constituent strength, I consider that it is not something to be recommended.

The second concern is her inconsistent use of the Generalized Alignment (GA). The given alignment constraint postulated by her is given as in (5).

(5) Disyllabic Constituent Alignment (Align-Di-L; Zhang, 1997, p. 308)

Align the left side of a TS domain with the left side of a disyllabic constituent when two or more TS domains occur.

In order to evaluate her use of GA, let's have the definition of it first.

(6) Definition of GA (McCarthy \& Prince, 1993, p. 80)

Align $\left(\right.$ Cat1, Edge1, Cat2, Edge2) $=_{\text {def }}$

$\forall$ Cat $1 \exists$ Cat 2 such that Edge 1 of Cat1 and Edge 2 of Cat 2 coincide.

Where

Cat 1 , Cat $2 \in$ PCat $\cup$ GCat

Edge1, Edge $2 \in\{$ Right, Left $\}$ 
The most important information read from (6) is that the category 1 is universal and that the category 2 is existential. One immediate not-that-major problem which I have is why and/or how a TS domain and a disyllabic constituent qualify as a prosodic category or a grammatical category. They are not the typical members for each of the two categories, so their qualification should be argued. Instead, this has been just assumed without any comment. Next, the unconventional stipulation of "when two or more TS domains occur" in (5) is not founded. Within my limited knowledge toward the practice of GA, the only things needed are just what (6) depicts. From a hindsight perspective, the function of this stipulation merely tries to rescue the maximally changed $2 * 3$ pattern from being non-harmonic. ${ }^{2}$ This statement applies at least to (35), (39a-b), (45), (47), and (74) of Zhang (1997).

The more serious problem is when the universal/existential relationship is articulated more specifically. None of the only two possible alignment constraints for (5) which are permitted by (6), that is, Align (TS, L, disyllabic constituent, L) and Align (disyllabic constituent, L, TS, L), is consistently practiced. ${ }^{3}$ Zhang's (1997, p. 328) (69) is going to be reproduced as a departure in order to see the chaotic use of GA. Even worse is, when the above two realizations are consistently applied, the wrong candidates would be chosen as the optimal ones, as shown in the undermentioned (8) and (9). In addition, in order for the optimal candidates to win out in Zhang's (69), she has stipulated that "it is worse to violate two equally ranked constraints than to multiply violate just one of those equally ranked constraints" (Zhang, 1997, p. 337, endnote 9). This tailor-for-particular-case is unsound and arbitrary. That the stipulation for her (69) makes no harm for her other tableaux is irrelevant and does not soften its arbitrariness in any extent.

(7) Reproduction of Zhang's (69)

\begin{tabular}{|c|c|c|c|c|c|}
\hline$\underline{\mathrm{wS}} \mathrm{W} \underline{\mathrm{wS}} \mathrm{S}$ & PTAS & $* 33^{4}$ & PTRS & Align-Di-L & $\operatorname{Max}^{5}$ \\
\hline a. $(23)(3)(223)$ & & $* !$ & $*$ & 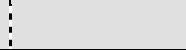 & $*$ \\
\hline b. $(\underline{23})(2 \underline{223})$ & & & $*$ & $* !$ & * \\
\hline c. $(223)(\underline{22} 3)$ & & & $* *$ & & $* *$ \\
\hline$\Leftrightarrow$ d. (222223 $)$ & & & $* *$ & 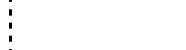 & $*$ \\
\hline e. $(23)(2 \underline{3})(23)$ & & & $*$ & *! & \\
\hline
\end{tabular}

\footnotetext{
${ }^{2}$ An asterisk means that the $2 \mathrm{~s}$ are more than one.

${ }^{3}$ Following Zhang's (1997) original alignment constraint formulation, I will not consider the R-to-R, L-to$\mathrm{R}$, or R-to-L edge pairings. As would be obvious from the following discussion, what truly matters are the universal-existential distinction and the constraint definition/evaluation stipulations. For more on the pairing of edge for GA, please refer to Kager (1999, p. 119).

${ }^{4}$ No sequential third tones (*33): No adjacent third tones are allowed. (Zhang, 1997, p. 307)

${ }^{5}$ Maximal Domain (Max): The maximal TS domain is two syllables in normal speaking rate but larger in more casual or faster style. (Zhang, 1997, p. 308)
} 
(7) has been the tableau for the sentence Lao gui xiang da san zou. 'The old ghost wanted to walk with an umbrella.' (老鬼想打傘走。). The parentheses indicate TS domains and the underlines disyllabic constituents. Both $(7 \mathrm{c})$ and $(7 \mathrm{~d})$ have been the optimal candidates because it has been assumed that when a suboptimal candidate is inferior to the optimal one only in the Max, the suboptimal is fine for the fast speech (Zhang, 1997, p. 308). The situation goes sour when the endnote 9 stipulation and the "when two or more TS domains occur" stipulation are abolished and either of which alignment constraints is carefully examined: the default (7c) is not directly available or even unavailable.

In (8), we first have Align (TS, L, disyllabic constituent, L) (abbreviated as AlignL (TS, disyllabic constituent)), which means that every TS's left edge coincides with some disyllabic constituent's left edge.

(8) (7) with Align-L (TS, disyllabic constituent)

\begin{tabular}{|r|l:l|l:l|l||}
\hline$\underline{\text { ws }}$ w $\underline{\text { ws S }}$ & PTAS & $* 33$ & PTRS & Align-L (TS, disyllabic constituent) & Max \\
\hline a. $(\underline{23})(3)(\underline{22} 3)$ & & $* !$ & $*$ & $*$ & $*$ \\
\hline b. $(\underline{23})(2 \underline{22} 3)$ & & & $*$ & $*$ & $*$ \\
\hline$(\Leftrightarrow)$ c. $(\underline{22} 3)(\underline{22} 3)$ & & & $* *$ & & $* * !$ \\
\hline d. $(\underline{22} 2 \underline{22} 3)$ & & & $* *$ & & $*$ \\
\hline e. $(\underline{23})(2 \underline{3})(\underline{2} 3)$ & & $*$ & $* * !$ & \\
\hline
\end{tabular}

To help identify the suboptimal candidate, I have deliberately marked this kind of output by putting the pointing hand between the parentheses. (8c) is rescued through the high speech rate, which is contrary to Zhang's (1997, p. 327) own understanding that $(8 c)$ is the output for the moderate speed. (8b) is wrongly selected as being optimal with (8d) which should originally occur in the fast speech (Zhang, 1997, p. 327). ${ }^{6}$

In (9), we have Align (disyllabic constituent, L, TS, L) (abbreviated as Align-L (disyllabic constituent, TS)), which means that every disyllabic constituent's left edge coincides with some TS's left edge.

(9) (7) with Align-L (disyllabic constituent, TS)

\begin{tabular}{|r|c:l|l:l|l||}
\hline$\underline{\mathrm{ws}} \mathrm{w} \underline{\mathrm{ws}} \mathrm{S}$ & PTAS & $* 33$ & PTRS & Align-L (disyllabic constituent, TS) & Max \\
\hline a. $(\underline{23})(3)(\underline{22} 3)$ & $\vdots * !$ & $*$ & & $*$ \\
\hline (国) b. $(\underline{23})(2 \underline{22} 3)$ & & & $*$ & $*$ & $* !$ \\
\hline c. $(\underline{22} 3)(\underline{22} 3)$ & & $* *$ & & $* ! *$ \\
\hline d. $(\underline{22} 2 \underline{2} 3)$ & & $* *$ & $* !$ & $*$ \\
\hline e. $(\underline{23})(2 \underline{3})(\underline{2} 3)$ & & $*$ & $*$ & \\
\hline
\end{tabular}

\footnotetext{
${ }^{6}$ Precisely speaking, then, (7) is an unsolved problem for Zhang's (1997) analysis.
} 
The optimal (9e) and the suboptimal (9b) are both not surface true. Interestingly, if the stipulations were revived, (9) would be the exact (7). Therefore, the superficial success of (7) is based on some unpersuasive manipulation of OT. ${ }^{7}$

Before I end this section, some thoughts about $* 33, \mathrm{Cl}^{8}$, and Max will be given in (10).

(10) Responses toward three more constraints in Zhang (1997)

a. For $* 33$, the so-called property of "being violable" of this constraint is not due to the inherence from OT. It is due to foot boundary (Shih, 1997, p. 117).

b. As will be shown, I will view $\mathrm{Cl}$ as the outcome of PF merger.

c. For Max, the maximally changed realization is derived by seeing a given string as a single application domain for the TS3 rule (Shih, 1997, p. 86 and further comments therein). ${ }^{9}$

I hope that through this examination, I have demonstrated the problematic side of Zhang's constraint-based analysis. In the next section, I am going to show that a much simpler and null-invention analysis is feasible.

\section{Resort to PF Merger}

Importantly, in order to make everything else being equal, all Zhang's (1997) judgments will be assumed in this section, though mine differ from hers from time to time. Moreover, as mentioned in (10c), the maximally changed pattern will not be further discussed. In the present case, this kind of pattern is theoretically less interesting.

From (1), the focus would be the special status of a preposition. Presumably, this status can be attributed to its feature composition being [-N, -V]. I then propose that there is a PF merger in Mandarin as in (11).

(11) Optional preposition PF merger in Mandarin

In Mandarin, a [-N, -V] can PF merge with a preceding constituent and form a new constituent if $\mathrm{PF}$ adjacency is respected. ${ }^{10}$

\footnotetext{
${ }^{7}$ The closeness between (7) and (9) above may make one conclude that Align-L (disyllabic constituent, TS) is the one used in Zhang (1997), but this conclusion is false. One is more than welcome to verify this assertion of mine (for I had reached this conclusion once).

${ }^{8}$ Clitic Dependency $(\mathrm{Cl})$ : A clitic cannot be separated from the TS domain of the preceding verb or preposition head. (Zhang, 1997, p. 307)

${ }^{9}$ The constraint ranking of the six constraints is: PTAS, *33, Cl » PTRS, Align-Di-L » Max (Zhang, 1997, p. 312).
} 
The product derived from the PF merger is seen as an immediate constituent for foot formation in Mandarin. ${ }^{11}$ The algorithm for footing adopted is provided in (12).

(12) Mandarin foot formation (Shih, 1997, p. 98)

a. Join immediate constituents into disyllabic feet. ${ }^{12}$

b. Scanning from left to right, join monosyllabic constituents into disyllabic feet.

c. Join any remaining monosyllables to neighboring feet.

The optionality of (11) accounts for two realizations in (1a). ${ }^{13}$ The nonspecification of a prepositional phrase in regards of constituent strength is replaced by a preposition's applying the PF merger or not, which is like a (phonological) unary feature's presence or absence. A presupposition from this proposal is that the PF merger (11) has to take place before the foot formation (12). This is achieved by means of the extrinsic ordering or the organization of morphological structure earlier than phonological form (Halle \& Marantz, 1993, p. 114). In sum, based on Zhang's (1997) data, the way to deal with the (avoidance of) TS can be visualized in (13).

\section{(13) Flow chart of TS operation}

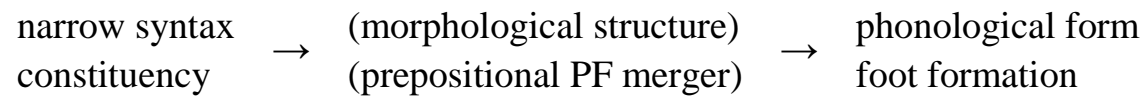

In (13), morphological structure and its association are put within the parentheses to indicate their optionality. That nothing new can be read from (13) is the beauty I am trying to argue for in this study. Thanks to the development of the Chomskian syntax

\footnotetext{
${ }^{10}$ The formal definition of PF merger in this paper is given in (i).

(i) PF merger (Halle \& Marantz, 1993, p. 116)

Merger...joins terminal nodes under a category node of a head...but maintains two independent terminal nodes under this category node.
}

Furthermore, the application of PF merger respects "PF adjacency" (Bošković, 2001, p. 84).

${ }^{11}$ A foot here is equal to what Chen (2000, p. 366 et seq.) terms a "minimal rhythmic unit".

${ }^{12}$ When one thinks more carefully on all TS3 data in the literature, immediate constituency cannot cover very well all of it. Because syntax conventionally only sees word and the bigger chunks, compounds, like shuiguo 'fruit' (水果; both syllables with T3), enter syntax without their sub-word structure being visible. Therefore, to say shuiguo can form a disyllabic immediate constituent is wrong-the term is a unit already. I believe that, due to this difficulty and other TS facts, Chen (2000, p. 380-386) argues that the TS3 rule in Mandarin is both lexical and post-lexical. And Chen's analysis suggests that Mandarin is a big support for the Lexical Phonology. However, against the backdrop of the interface inquiry, especially phase and multiple spell-out, Scheer (2008) argues that the Lexical Phonology has to go because it has some built-in redundancy. We are then left with a dilemma. As this question is beyond the scope of this paper, I will play vague and stick with Shih's (1997) algorithm for the time being and leave this issue for future pursue.

${ }^{13}$ I generalize the idea of optionality for phonology (Vaux, 2008, p. 41-44) to morphology. 
and the Halle-Marantz morphology, we are more equipped than ever to cope with the interface issues. It is time for us to choose the appropriate ones among these weapons, not to create more. Below I am going to demonstrate with some instances from Zhang (1997) and see some refinement.

Let's first begin with the derivation of $(1 \mathrm{a} \alpha)$. If the PF merger does not occur, the derivation would be that in (14).

(14) Derivation of (1a $\alpha)$ without the PF merger

a.

[gou3 [[bi3 ma3] xiao3]]

b. (gou3((bi3ma3)xiao3)) or ((gou3(bi3ma3))xiao3)

c.

gou3 bi 2 ma2 xiao3

In (14a), the constituency is given as the result of narrow syntax. In (14b), because bi $m a$ is an immediate constituent, it forms a disyllabic foot. The remaining monosyllabic constituents are far apart, so (12b) is not applicable. (12c) will then include gou and xiao into the existent foot starting from either of them. The TS3 rule then applies cyclically outwards, which results in (14c).

If the PF merger occurs, the derivation would be that in (15).

(15) Derivation of ( $1 \mathrm{a} \alpha)$ with the PF merger

a.

[gou3 [[bi3 ma3] xiao3]]

b.

[[gou3 bi3] ma3 xiao3]

c.

(gou3 bi3)(ma3 xiao3)

d.

gou2 bi3 ma2 xiao3

(15a) is the same as (14a). (15b) is the application of PF merger, which forms gou and $b i$ as post-syntactic constituent. This constituent will then be an immediate constituent and make a disyllabic foot. (12b) this time is applicable to the remaining string. After that, (12c) is of no use. The cyclic application of the rule produces the output (15d).

(14) and (15) basically complete my analysis. The gist of my analysis is plain: allow a preposition to have the freedom of PF merger in Mandarin, where PF merger is now a familiar and hot topic. Below the discussion continues with those (seemingly) problematic cases. 
Under the present PF merger analysis, that the sentence Gou bi wo xiao. 'The dog is younger than me.' (狗比我小。; Zhang, 1997, p. 297) cannot have the SR 2323 is not understandable since bi could PF merge with gou and the two thus form an immediate constituent and then a disyllabic foot. To account for this, I revise (11) as (11') based on Zhang's (1997, p. 296-297) observation that there is a proform following $b i$.

\section{(11') Optional preposition PF merger in Mandarin}

In Mandarin, a [-N, -V] can PF merge with a preceding constituent and form a new constituent if PF adjacency is respected, except when the given $[-\mathrm{N},-\mathrm{V}]$ is followed by an overt and adjacent D.

The revision is possible because under the $\mathrm{D}$ (eterminer) $\mathrm{P}($ hrase) hypothesis (Abney, 1987; Baker \& Hale, 1990) a proform is a D. The $m a$ in (1a $\alpha)$ is also a DP under the DP hypothesis, but it lacks an overt and adjacent D for the preceding bi. So, there is no change for the derivation in (15) with (11'). As for the sentence Gou bi wo xiao., the PF merger is not applicable (wo is an overt and adjacent D for the preceding bi), so only the SR 3223 is produced.

In Zhang's discussion of the constraint $\mathrm{Cl}$, she has mentioned a verb-classifiernoun construction. To deal with the TS of this construction, I borrow the spirit of Xu (1999) and see the construction has another obligatory PF merger going on between a bare classifier and its preceding verb. Therefore, the verb phrase xiang mai ba san '(I) want to buy an umbrella' (想買把傘; Zhang, 1997, p. 307) have mai and ba as a postsyntactic constituent, which provides the reason why the SR 2323 is not derivable. ${ }^{14}$

For Zhang's (1997, p. 334) (80), Shih's (1997, p. 91-94) “initial cycle” is needed. Initial cyclicity makes flat all the more embedded foot structure below a chosen foot. Since the concern is not to derive all the possible TS outputs, in (16) below, only the most relevant footing will be given. The footing in (16) is the interaction of the application of PF merger and the "non-deterministic" (Shih, 1997, p. 98) nature of (12c). The non-determinacy gives an unfooted syllable to be incorporated with the foot in front of or in back of it. And in the present case, this unfooted syllable ye is incorporated into the foot following it.

\footnotetext{
${ }^{14}$ The PF merger analysis here is so similar to Shih's (1997, p. 110-112) clitic analysis. I, however, hesitate to make this connection. For one thing, cliticization seems to implicate that it must be applied, but from the above discussion, optionality has to be granted. (I think that to account for cross-Sinitic TS phenomena, this freedom should also be allowed.) For another thing, "[c]lictics can attach to material already containing clitics" (Zwicky \& Pullum, 1983, p. 504), why shouldn't a proform cliticize to a host which has been cliticized by a preposition, if the two categories are both the target of cliticization? Whether this separation of PF merger on the one hand and cliticization on the other hand is valid or not, I leave it for future research.
} 
(16) Footing of Lao ma ye dei gei gou yao.

“The old horse will also be bitten by a dog.' (老馬也得給狗咬。)

(lao ma)(ye (dei gei))(gou yao)

The usual application of the TS3 rule will give out the SR 2332323 or 2232323 (TS3 across foot boundary is optional (Shih, 1997, p. 85-86)), not Zhang's 2322323. However, the initial cycle allows us have two alternatives for the tri-syllabic foot's TS rule application: starting from the inner foot (without initial cyclicity) or the outer one (with initial cyclicity). The inner first gives the SR 2232323 (from 2332323); the outer first gives Zhang's SR 2322323. This strategy of Shih's also makes Zhang's (1997, p. $325,332)(62)$ and (75) accountable.

I end this section with the string bi gou xiao 'smaller than dog' (比狗小; Zhang, 1997, p. 295). In Zhang's analysis, bi is a preposition and takes gou as its complement. Because there is nothing preceding $b i$, the PF merger does not function. The expected SR should only be 223 . However, there is another realization provided by Zhang: 323 . To derive this realization, I may borrow the idea from Xu (1992, p. 74-78): because gou is a noun (contra to a proform) in the middle of a prepositional phrase, the noun may initiate its sandhi domain, which provides the footing (bi (gou xiao)). From this footing, the realization 323 is then derivable. Or, if the SR 323 is realized as being contrastive, Shih's (1997, p. 112-116) "emphatic boundary" can be said to function. An emphatic boundary is a left foot parenthesis, that is (, established before an emphatic element. An emphatic left footing cannot be restructured by the footing algorithm, but it can undergo initial cyclicity. Once again, the probable use of $\mathrm{Xu}$ (1992) echoes with what has been mentioned earlier in the text-we have the tools already and it is time to make use of them.

\section{Conclusion}

Using Zhang (1997) as the starting point, I first argued that her analysis has been based on the questionable assumption of constituent strength and the misused GA, plus some stipulations about OT. Then, together with the narrow syntax, PF merger, and foot formation algorithm, I hope that I have displayed that what theoretical achievement we have now has prepared us more ready than ever to re-examine the previous literature and to re-shape the persistent questions into more simplex realizations. Along the way, a robust point has been re-ensured: in order to understand better the interface between phonology and syntax, the formal syntactic structure has to be more carefully looked after (cf. Lasnik \& Lohndal, 2010, p. 48). Despite of the current interest in interface, to encapsulate all the joining forces into a parallelevaluation model, like OT, cannot be right because "what needs to be explained becomes the explanation" (van der Hulst, 2004, p. 237, emphases in original). The interest should, instead, push us harder to scrutinize the interwoven forces and put each of them back to its place. 
For my synthetic analysis, there are certainly things to work on as well. For example, can the two mergers for preposition and classifier be subsumed under more general principle(s)? ${ }^{15}$ Another task can be: is the analysis presented here adaptable enough to operate on the other (Sinitic) TS systems? These and more are important issues ahead.

\section{References}

Abney, S. P. (1987). The English noun phrase in its sentential aspect. Doctoral dissertation, Massachusetts Institute of Technology.

Baker, M., \& Hale, K. (1990). Relativized Minimality and pronoun incorporation. Linguistic Inquiry, 21(2), 289-297.

Bošković, Ž. (2001). On the nature of the syntax-phonology interface: Cliticization and related phenomena. Amsterdam, the Netherlands: Elsevier.

Chen, M. Y. [陳淵泉] (2000). Tone sandhi: Patterns across Chinese dialects. Cambridge, England: Cambridge University Press.

Cinque, G. (1993). A null theory of phrase and compound stress. Linguistic Inquiry, 24(2), 239297.

Grimshaw, J. (2005). Extended Projection. In J. Grimshaw, Words and structure (pp. 1-73). Stanford, CA: CSLI Publications.

Halle, M., \& Marantz, A. (1993). Distributed Morphology and the pieces of inflection. In K. Hale \& S. J. Keyser (Eds.), The view from building 20: Essays in linguistics in honor of Sylvain Bromberger (pp. 111-176). Cambridge, MA: The MIT Press.

Kager, R. (1999). Optimality Theory. Cambridge, England: Cambridge University Press.

Lasnik, H., \& Lohndal, T. (2010). Government-binding/principles and parameters theory. Wiley Interdisciplinary Reviews: Cognitive Science, 1(1), 40-50.

McCarthy, J. J., \& Prince, A. (1993). Generalized Alignment. In G. Gooij \& J. van Marle (Eds.), Yearbook of morphology 1993 (pp. 79-153). Dordrecht, the Netherlands: Kluwer Academic Publishers.

Scheer, T. (2008). Spell out your sister!. In N. Abner \& J. Bishop (Eds.), Proceedings of the $27^{\text {th }}$ west coast conference on formal linguistics (pp. 379-387). Somerville, MA: Cascadilla Proceedings Project.

Shih, C. [石基琳] (1997). Mandarin third tone sandhi and prosodic structure. In J. Wang [王嘉 齡] \& N. Smith (Eds.), Studies in Chinese phonology (pp. 81-123). Berlin, Germany: Mouton de Gruyter.

Van der Hulst, H. (2004). Phonological dialectics: A short history of generative phonology. In P. van Sterkenburg (Ed.), Linguistics today: Facing a greater challenge (pp. 217-242). Amsterdam, the Netherlands: John Benjamins Publishing Company.

Vaux, B. (2008). Why the phonological component must be serial and rule-based. In B. Vaux and A. Nevins (Eds.), Rules, constraints, and phonological phenomena (pp. 20-60). Oxford, England: Oxford University Press.

\footnotetext{
${ }^{15}$ If classifiers could somehow be incorporated into Grimshaw's (2005, p. 4) Extended Projection for D, the two PF mergers might be collapsible: both of them are $[-\mathrm{V},+\mathrm{N}]$ with a preposition bearing a functional feature F2 and a D F1. And the functional feature might also hint at the obligatoriness of the two mergers. Whether this collapse is substantive or not, I leave it for future research.
} 
Wee, L.-H. [黃良喜] (2008). Opacity from constituency. Language and Linguistics, 9(1), 127160.

Xu, D. [許德寶] (1992). Mandarin tone sandhi and the interface study between phonology and syntax. Doctoral dissertation, University of Illinois at Urbana-Champaign.

Xu, D. B. [許德寶] (1999). A syntactic account for the inseparability of the verb and the classifier in the structure $\mathrm{V}+\mathrm{C}+\mathrm{N}$ in tone sandhi. Journal of the Chinese Language Teachers Association, 34(3), 77-90.

Zhang, N. [張寧] (1997). The avoidance of the third tone sandhi in Mandarin Chinese. Journal of East Asian Linguistics, 6(4), 293-338.

Zwicky, A. M., \& Pullum, G. K. (1983). Cliticization vs. inflection: English n’t. Language, 59(3), 502-513. 
